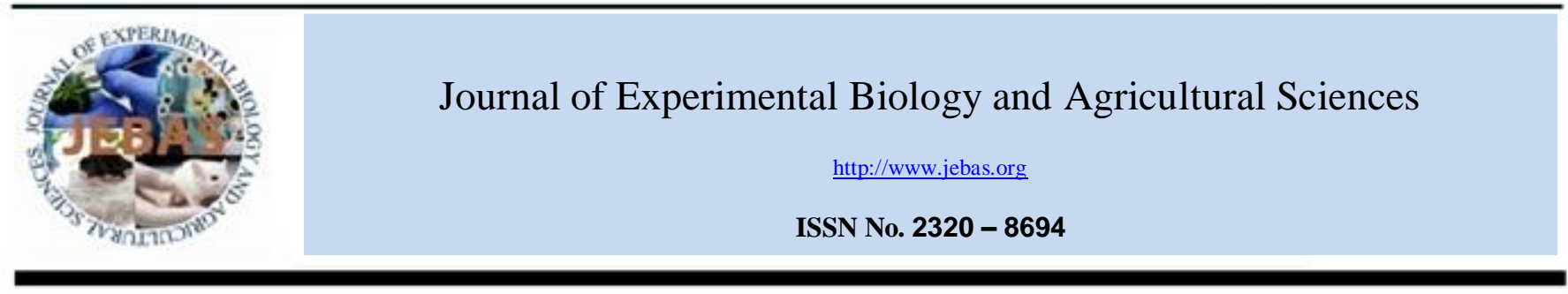

\title{
FACTORS RESPONSIBLE FOR UNDER EXPLOITATION AND PROMOTION OF AGRICULTURE IN OF THE LOWER AND UPPER UELE DISTRICTS
}

\section{Bertin Richard LANDA ZENGBE}

Bertin Richard LANDA ZENGBE, Chef de Travaux, Université de l’Uélé/ISIRO, Province Orientale, République Démocratique du Congo

Received - June 02, 2015; Revision - June 11, 2015; Accepted - June 24, 2015

Available Online - June 26, 2015

DOI: http://dx.doi.org/10.18006/2015.3(3).307.315

\section{KEYWORDS \\ Uele District \\ DRC \\ Agriculture \\ Under exploitation \\ Agricultural policies}

\begin{abstract}
Agriculture of the upper and lower Uele district, Democratic Republic of the Congo is still under exploitation, present study has been carried out to exploit the factors responsible for the under exploitation of Uele district agriculture. This study also aimed to find out possible solution to overcome these factors and promote the agriculture of study area. Results of the study revealed the various factors like social, political, administrative, economic, environmental and technical field are responsible for the under exploitation of the Lower and Upper-Uele districts agriculture. To overcome these problems like other countries agricultural sector should have its own solid budget. With this conscientization and planification of the adapted agricultural policies and politics are required on the priority basis. Furthermore, popularization and distribution of genetically developed seeds or rustic parents, empowerment of the agriculture based research, relaunching of agriculture, formation and distribution of market values of agriculture product and agrarian reform literacy are the possible solution for the promotion of Lower and Upper Uele districts agriculture. Proper dissemination of well acceptable agricultural policies between farmers and general population is must. For sustainable agricultural development, a strong complementarity between public and private investors is necessary.
\end{abstract}

* Corresponding author

E-mail: bertilanda@gmail.com (Bertin Richard LANDA ZENGBE)

Peer review under responsibility of Journal of Experimental Biology and Agricultural Sciences.

Production and Hosting by Horizon Publisher (www.myvision.webs.com/horizon.html).

All rights reserved.
All the article published by Journal of Experimental Biology and Agricultural Sciences is licensed under a Creative Commons Attribution-NonCommercial 4.0 International License Based on a work at www.jebas.org.

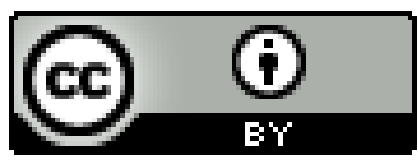




\section{Introduction}

Agriculture is a vital sector in the Democratic Republic of Congo (DRC), revolution in DRC agricultural policies is highly recommended because this sector has very high potential of growth and income generation. Agriculture provides a direct employment to more than $50 \%$ of the Congolese population and accounted in average of 40 percent of total GDP which produces the largest percentage of total value added (Ulloa et al., 2009; World Bank Databank, 2009; Otchia, 2014a; Otchia, 2014b; Jeníček \& Grófová, 2015). Favorable agroclimatic diversity and high rain favor the development of huge agricultural potential in DRC. Agroclimatic conditions of the DRC strongly favor the culitivtion of palm, rubber, coffee, cocoa, banana, and cassava trees while the zones of savannas favor the cultivation of cotton, cereals and legumes. Though all the agroclimatic conditions favor the development of agricultural potential in DRC but after that also at present agricultural of DRC is underused. Presently country has 80 million hectares of arable land but out of this only $9-10 \%$ is under cultivation (Chausse et al., 2012). This statement is enough to explain the present situation of agriculture in DRC.

The Lower and Upper Uele regions are located in the North of the Democratic Republic of Congo (DRC). Agriculture of Uele region is still unproductive and less exploited because of inconsistent and uncoordinated agricultural policies. This paper thus aim to assess what are the factors responsible for the under exploitation of upper and lower district agriculture and what strategies or adequate solutions can be formulated to promote study area agriculture? Apart from the introduction and the conclusion, the present article articulates around the factors of the under exploitation and strategies or adequate solutions for the promotion of agriculture in the Districts of Lower and Upper Uele.

\section{Materials and Methods}

\subsection{Study area}

According to the Monograph of the Eastern Province, (2005), Lower and Upper Uele regions are located in the Uele basin of the Eastern Province and have latitude $3^{\circ} 43^{\prime} \mathrm{N}$; longitude $24^{\circ}$ $30^{\prime}$ E, altitude varying between 200 and $1500 \mathrm{~m}$. Ferrasoils and ferrisoils (characteristic soil of savanna forest) have been reported from the study area, this soil favor the development of agriculture and crop cultivation.

\subsection{Methodology}

Present study was conducted in two districts namely the Districts of the Lower Uele and Upper Uele of the DRC over three years period (March, 2012 to March, 2015). A total eight territories viz Ango, Bambesa, Buta, Poko of the LowerUeleand Dungu, Niangara, Rungu, Wamba of the UpperUelewere surveyed for the study. Total 480 households including 60 practicing agriculture were interviewed for generating suitable information. Along with this additional information for this study were generated by critical analysis of available conferences, symposia and communal meetings reports along with well formulated questionnaires, interview and the participatory observation.

All the generated information's were statically analyzed at frequency (f), probability, percentage (\%) and chi-square level. The comparative approach will be used to analyze results on the basis of quantitative and qualitative level. Following, Porkess (1988), qualitative data were classified in various classes like low, medium, high, elevated, etc. while the quantitative data are classified by numerical values. The criteria of assessment used according to Donald (2012).

\section{Results and Discussion}

3.1 Factors responsible for under-exploitation of the agriculture of Lower and Upper Uele districts

Both the studied districts have almost identical geographical, social and economical conditions. Both are situated on the bank of Uele river and sharing its water for agriculture. Civilizations of these two are highly influenced by SudanEgyptian culture and have been explored by same European and Belgian conquistadors. Both districts have almost similar conditions and because of this they have common social, political, economical, administrative and environmental under exploitation factors.

\subsubsection{Social factors of under exploitation}

Demography, land system, conscience, mentality, education, supervision, organization, personal conflicts and insecurity are the some common social issues which are responsible for the under exploitation of the upper and lower Uele districts agricultural.

\subsubsection{Demography of upper and lower Uele districts}

In spite of the increasing demography of DRC, the population density of the lower and upper Uele district is less. According to the Monograph of the Eastern Province (2005), the population density of lower Uele Districts was $6-7 / \mathrm{km}^{2}$ while it was $17 / \mathrm{km}^{2}$ for the Upper Uele district. The population growth rate of Uele districts was reported only $0.5 \%$ during the period of 2005 to 2010. Above mentioned reports revealed that lower and upper Uele districts are weakly populated by a stagnant population. This available low demography discourages all the economic initiative taken by government for the long term profitability of the certain density populations (Anatole, 1967). By considering this weak population growths of these areas some time government may not formulate any special agricultural policies for these area and this might be a cause of under exploitation of area agriculture. 
3.1.1.2 Land system

The land acquirement in these two districts is principally depends on the customary inheritance and every one cultivated the land of their forebears which they received as an ancestral property. In these two districts these landowners have full right to transfer land to anybody; in this manner any strangers can established or acquired land by paying a symbiotic value to the landowner. The recipient cannot pretend any right of property this transfer is for a short period.

In these areas land always belongs to the community and governmental authorities such as chief of collectivity or commissioner of territory or chief of locality are always work as beforehand consultant. Once the agreement between the buyer and seller signed, an amount poured to the chief of the village, a traditional ceremony will organized at the time of the official discount of the earth patch. After agreement the customary persons are responsible for introducing the recipient to the land-registry service and at this time they can demand for concession. An investigation on the availability of land decide the level of concession (demarcation) and sometime this determination can be influenced by the rights of an individually or collectively inhabitants compensation. By this procedure, the state purchases the common law on this earth. Finally, a contract of concession is signed between the individual and the state. To the continuation of this investigation, the system fundamental customary duct for the hoarding of the earth by the customary owner that, in principle doesn't valorize their earth and prevent by simple jealousy, the non-original to exploit the earth. This manner to make brings to the under-exploitation of agriculture in the districts of the Lower and Upper Uele.

\subsubsection{Conscience or mentality}

The conscience can be defined as a mental strength and it is be categorized at three levels viz conscience zero (0) that is attentiste (partisan of a wait andsee policy); conscience lower than zero (-1) that is naive (anti-development) and the conscience superior than zero $(+1)$ which is revolting (favorable to the development). Often the too low consciences is characterized by the innocence and wait and see policy, which can be repress by laziness, tribalism, fetish, drunkenness, jealousy, sorcery, superstition and non organization while the ignorance can be expressed by the absence of information and training.

Results of the different level of conscience in the population of lower and upper Uele district have been represented in table 1 . Among the total 480 interviewed respondents, $69.17 \%$ of the respondents shows attentiste type of conscience while $26.25 \%$ respondent were showing naïve type of conscience. Only $4.58 \%$ of the interviewed respondents were showing revolting type of conscience, this much low percentage of revolting conscience shows the attitude of lower and upper Uele district population, they are either not want any changes in the persisting governmental policies or they are not bothered about the development. Results of table 1 clearly revealed an inadmissible way of the Uele district population. This factor is most crucial factor for the under exploitation of Uele district agriculture. However, strength has to be recognizing the existence of passivity sometimes it may be due to the ignorance. The peasants having either attentiste or naïve types of conscience are not having sufficient knowledge of modern technique and it caused under exploitation of agriculture..

\subsubsection{Level of study}

Results of the study level of investigated households are represented in table 1 . About half $(47.50 \%)$ of the investigated households have education up to primary level, while only $5 \%$ of the population have complete academic qualification. For knowing the policies and advanced technique related to the modern agriculture, a certain level of education is necessary. Overall result of the education level study suggested that $64.16 \%$ of the respondents have either illiterate or have only primary education.

In general, lower education level has negative effect on the adoption of the recent technology by farmers. These conditions became worse in the case of adult women respondents who contribute primordial way to the agricultural production and to the food security. In conclusion low education level prevents the household respondents by appreciating the value and advantages of improved agricultural technologies. Furthermore, level of education has direct impact on knowledge, expertise, attitudes and on the behavior of the farmers, the lower education level that prevails in the lower and Upper Uele district is mirrored by the under - exploitation of agriculture.

3.1.1.5 Agricultural supervision and monitoring in the studied areas

Agricultural monitoring by agricultural monitors in the lower and high Uele district was completely disappeared. Along with this, availability of the improved seed as well as products phytosanitaires is also rare enough. Knowledge of the new improved agricultural techniques was also reported in the scarcity in all the surveyed respondents (Table 1). Most of the investigated households (94.58\%) accepted that they have not properly supervised and they publicly denounced the weakness of the popularization of agricultural research. Because of this lot of agricultural support services hardly function. The deficiency of the supervision peasants is attested in part in the insufficiency of the training of the agricultural agents. The content of the training doesn't answer the real needs of the Congolese agriculture. 
Table 1 Effect of the various investigated social factors on the exploitation of Lower and Upper Uele districts agriculture (Total interviewed household $=480$ ).

\begin{tabular}{|c|c|c|c|c|}
\hline $\begin{array}{l}\text { Various Investigated } \\
\text { Social Factors }\end{array}$ & \multicolumn{2}{|c|}{ Tested Parameters } & $\begin{array}{c}\text { Number of respondent with } \\
\text { particular response }\end{array}$ & $\begin{array}{l}\text { Percentage of the } \\
\text { obtained response }\end{array}$ \\
\hline \multirow[t]{3}{*}{ Conscience } & \multicolumn{2}{|c|}{ Attentiste (0) } & 332 & 69.17 \\
\hline & \multicolumn{2}{|c|}{ Naive (-1) } & 126 & 26.25 \\
\hline & \multicolumn{2}{|c|}{ Revolting (+1) } & 22 & 04.58 \\
\hline \multirow[t]{4}{*}{ Study } & \multicolumn{2}{|c|}{ Illiterate } & 80 & 16.67 \\
\hline & \multicolumn{2}{|c|}{ Primary } & 228 & 47.50 \\
\hline & \multicolumn{2}{|c|}{ Secondary } & 148 & 30.83 \\
\hline & \multicolumn{2}{|c|}{ Academic (Graduate or above) } & 24 & 05.00 \\
\hline \multirow{3}{*}{$\begin{array}{l}\text { Supervision, } \\
\text { popularization, } \\
\text { research \& inputs }\end{array}$} & \multicolumn{2}{|c|}{$\begin{array}{l}\text { Non supervision, research and } \\
\text { popularization }\end{array}$} & 454 & 94.58 \\
\hline & \multirow[t]{2}{*}{ Inputs } & Degenerate seeds & 470 & 97.92 \\
\hline & & Degenerate races & 434 & 90.42 \\
\hline \multirow[t]{3}{*}{ Organizations } & \multicolumn{2}{|c|}{ Individual } & 468 & 97.50 \\
\hline & \multicolumn{2}{|c|}{ Associative } & 12 & 02.50 \\
\hline & \multicolumn{2}{|c|}{ Solidarity } & 456 & 95.00 \\
\hline \multirow{3}{*}{$\begin{array}{l}\text { Conflicts and } \\
\text { insecurity }\end{array}$} & \multicolumn{2}{|c|}{ Natives with the Mbo'roroses } & 326 & 67.50 \\
\hline & \multicolumn{2}{|c|}{ Between Natives } & 156 & 32.50 \\
\hline & \multicolumn{2}{|c|}{ Insecurity (LRA) } & 64 & 13.33 \\
\hline
\end{tabular}

These districts face some problems like unavailability of the qualified researchers along with financial facilities. Along with this all the available researchers also did not have accurate objectives related to the agricultural research and majority of them are aged and not familiar with the modern agricultural techniques. Furthermore, these two districts have insufficient agricultural inputs and most of the available seeds (97.92\%) and races $(90.42 \%)$ currently used are very old and degenerate, dragging a sensitive decrease in the agricultural. Above mentioned factors are the major limiting factors for the upper and lower Uele districts agriculture and reduced the agricultural production and income.

\subsubsection{Organization}

Agriculture is not a result of individual activity, it needs lot of group activities and for that it required an organization. Results presented in the table 1 shows the various level of agricultural organization. Majority of the interviewed households (97.5\%) worked individually but among these $95 \%$ believed in solidarity. A small percentage $(2.5 \%)$ of the interviewed respondents joined forces in agricultural activities. Nevertheless, the system of the cooperatives is not anchored and only few cooperative associations have been survived in both the districts. Yet, it is indispensable that the community Congolese farmers especially in the districts of the Lower and Upper Ueleintegration of this cooperatives culture and solidarity in their habits to fight the under-exploitation of agriculture observed.

\subsubsection{Conflicts and insecurity}

Various degrees of conflicts and insecurity were recorded in the Lower and Upper Uele districts (Table 1). These are the motives that hinder a responsible agricultural exploitation.

Results presented in table 1 represent two level of conflict in the Districts of Lower and Upper Uélé. First level represented autochthonous population (67.5) and it consist by majority of the farmers and Mbo'roro"peuls" (breeders). The second level of conflicts was represented by the native population and it consisted by small scale breeders and farmers. Members of this group are in small number (32.5\%) and they have their field around the village and rest of the time let their beasts wanders everywhere. These conflicts prevent good workings order of the agriculture exploitation. In addition, $13.33 \%$ of insecurity is caused by LRA men, which constitutes one of the reasons that push the peasants to leave or run away from their village in search of security. All these conflicts and insecurities are the crucial factors that entail the under-exploitation of agriculture in the Districts of Lower-Ueleand Upper-Uélé.

\subsubsection{Technical factors of under exploitation}

Use of technology facilitate the high degree exploitation of available resources with this technology also differentiated the level of exploitations it can be manual, harnessed culture (by renting or property) and motorized. 
On the behalf of used technology agricultural sectors can be well distinguish in modern and traditional. These two are differ in obtained results, management and used technology. Modern agricultural sector is strongly mechanized and have very high capital investment with salaried employees for optimizing maximum profit and production. Most of the modern agroindustries used the highly advanced technology for suitable and measurable productions while in traditional agriculture sector farmers used rudimentary equipment with little agricultural inputs (fertilizer, selected seeds and pesticides) on small land in the form of polyculture. The development of the production in the traditional sector is made according to an operating system approach. In present survey most of the respondents used traditional farming operating system approaches as an existence path of agriculture. In present survey most of the respondents used traditional farming approaches for maintaining the existence of agriculture (Table 2). Majority of the interviewed households $(92.92 \%)$ resort only traditional agriculture techniques characterized by the polyculture while only $7.08 \%$ of the respondents practiced by modern agricultural techniques determined by the monoculture.

Result of the technology used in studied area clearly revealed that farmers of the studied area have not adopted the modern agricultural techniques suitable for the local conditions. Results of the research don't permit to find technological solutions adapted to the whole range of the socio-economic and agro-ecological conditions that exists in the investigated regions. Absences of technological solutions as often mentioned hinder the agricultural development. Diffusion of the advanced agricultural techniques and available technology can overcome the existing difficulties and can become popularized user friendly solution. The insufficiency of popularization and formation services due to the weak technological knowledge in the farmers is considered to be one of the main factors that hinder the adoption of the improved technologies. This constraint could be surmounted if the maximum farmers are facilitated to the knowledge.

Results related to the use of machinery in agriculture have been given in table 2. Majority of the interviewed farmers (99.17\%) used manual facilities or rudimentary tools that push them to achieve small surfaces not exceeding a hectare. Only $0.83 \%$ of the interviewed respondents used advanced mechanical tools and covered the large areas. Often, the facilities or tools as well as the agricultural machinery used are very old and traditional. Most commonly used agricultural equipments are hoe, machete, ax, file and rake (ACF 2008). Use of these types of traditional equipment are unproductive, and played an important role in the under exploitation of lower and upper Uele districts agriculture.

\subsubsection{Economic factors of under exploitation}

The important economic factors which are responsible for the under exploitation of upper and lower Uele district have been discussed in the table 2. All the interviewed households
(100\%) affirm the problem associated with the allocation of small agriculture budget, weak investment in agriculture, unavailability of suitable infrastructure related to transportation, conservation, storage, energy and transformation. All the respondents accepted that they did not received proper information related to market, bank and agricultural credit concession and because of this they are not aware about the recent agricultural trends. Among the studied household $86.25 \%$ accepted the poor conditions of the roads in studied areas and it badly affect the transportation between producers and consumers. Bicycle is the most common mode to transport their agricultural products. This unavailability of the transportation punished the producers and most of the time these producers kept their agriculture product with them or they sell it to the local purchaser on the price imposed by them. It can drag modification in the price of their agricultural product during the process of merchandising. Thus, the low price imposed by these mediators discourage the producers to not to produce and brings about the under-exploitation of agriculture.

Often, the public expenses dedicated to agriculture takes on a large subsidies farm, which hardly have any available financing for the creation of new holdings. Nevertheless, the specificity of agriculture, as the demand of country credits to finance the yearly harvests and elevated the risks that associated the exploitation, limit the role that the existing institutions of micro financing and their methods of loans can play to finance the country credits and the investments of the small operators. According to the information generated from FAO special program for food security (PSSA), majority of the farmers of 22 weak income country (PFRDV) face problems such as availability of the chemical fertilizers, suitable agriculture inputs and availability of the fodder for cattle (Tshonda et al., 2014). These problems are directly associated with the unavailability of the credit for agriculture, scattering of the agricultural land, unavailability of infrastructure, transportation and lack of efficiency. At the level of commercialization and management, the state controlled societies have exclusive rights of the distribution and merchandising of inputs. Absence of good roads as well as insufficiency of the storage has constituted major problems in the Districts of Lower and Upper Uele. They have even sometimes prevented the sale of entire harvests. Most of the farming roads are impassable during a good part of the year.

According to the agricultural raise plan 1982 - 1984, Zaire (present D.R.Congo) has been considered as the country of worst roads and it doesn't allowed to its peasants to sell their productions in open market (DADR, 1992). Furthermore, these poor road conditions are non motivational for the farmers and pushed farmers to produced food required for his own family consumption. As a result of above mentioned facts total agriculture production of the country reduced up to critical level. This thing impoverishments the surrounding farming as well as exodus the young generation toward the urban centers where they expect to find a better way of live. 
Table 2 Effect of various technical, economic, political, administrative and environmental factors of the exploitation of Uele districts agriculture (Total interviewed household $=480$ ).

\begin{tabular}{|c|c|c|c|}
\hline $\begin{array}{l}\text { Various Investigated } \\
\text { Factors }\end{array}$ & Tested Parameters & $\begin{array}{l}\text { Number of respondent } \\
\text { with particular response }\end{array}$ & $\begin{array}{l}\text { Percentage of the obtained } \\
\text { response }\end{array}$ \\
\hline \multirow[t]{2}{*}{ Techniques } & Monoculture (Modern) & 34 & 7.08 \\
\hline & Polyculture (Traditional) & 446 & 92.92 \\
\hline \multirow[t]{2}{*}{ Utilized facilities or tools } & Manual & 476 & 99.17 \\
\hline & Mechanical & 4 & 0.83 \\
\hline \multirow[t]{5}{*}{ Economic } & $\begin{array}{l}\text { Unavailability of the budget or low } \\
\text { budget }\end{array}$ & 480 & 100 \\
\hline & Weak investment & 480 & 100 \\
\hline & $\begin{array}{l}\text { Lack of infrastructure (Conservation, } \\
\text { energy, } \\
\text { and transformation) }\end{array}$ & 480 & 100 \\
\hline & $\begin{array}{l}\text { Poor mode of communication } \\
\text { (Information, bank and agricultural } \\
\text { credit }\end{array}$ & 480 & 100 \\
\hline & Bad condition of road & 414 & 86.25 \\
\hline \multirow[t]{3}{*}{ Harassments } & Administrations & 118 & 24.58 \\
\hline & Customary & 224 & 46.67 \\
\hline & Police & 138 & 28.75 \\
\hline \multirow[t]{2}{*}{ Type of vegetation } & Forest / Forest gallery & 340 & 70.83 \\
\hline & Savanna & 140 & 29.17 \\
\hline
\end{tabular}

These above mentioned facts are also applicable for the household conditions of the Districts of Lower and Upper Uele. Among the various infrastructures, transportation doesn't permit transportation of agricultural products from the regions where it is excess to the regions where it is shortage. The period of localized soldering, illustrates the severity of strangling bottlenecks in the sector of transportation and the fragmentation of the agricultural market.

The insufficiency of the communication means has the tendency to limit, for many producers the possibility to approaching the markets and get information or to render the access to the inputs was very difficult and expensive. These efforts have negative effects on the margins of the producers. The absence of storage means amplifies the seasonal variations on the markets and aggravates the losses after the harvests and it can be drag the under-exploitation of agriculture.

\subsubsection{Political and administrative factors of under exploitation}

The politico-administrative factors can be noticed through the lack of political will and it can be explained itself by the administrative, customary and police harassments that embarrass the good development of agriculture. Results presented in the table 2 presented the different level of harassments recorded in the Lower and Upper Uele districts.

Result of the study revealed that half of the respondents were face the customary harassments $(46.67 \%)$; these harassments were associated with the hoarding of the land, tribalism and the jealousy of customary chiefs. This was followed by police harassments $(28.75 \%)$, in which these respondents face the problems associated with the barrier for the taxes and ration. Among the surveyed households $24.58 \%$ were suffered by administrative factors concerned with the different "salongo" to build, either class rooms, health centers or maintain the road. These three levels of harassments made the investigated population feel ill at ease for the practice of agriculture. Often, these harassments entail the farming exodus and prevent the development of agriculture in the farming environment. Currently, in the institutional context, the Congolese agriculture suffers from a follow-up lack in the politics of development.

According to the agricultural raise Plan 1982-1984, the absence of a deepened reflection on the agricultural problems has prevented the development and the setting in work of a real planning of the agricultural actions. For this fact, until today, an absence of the definition of the objectives and the means of coordination is still noticed between the authorities and the private sector, and of the insufficient studies for some projects. To the point of management and control, some hiatuses also persist at the level of structures and men.

\subsubsection{Environmental factors of under exploitation}

The types of vegetation exploited by the investigated households are presented in table 2. In upper and lower Uele districts the most exploited vegetations are the forest/or forest gallery $(70.83 \%)$ and it was followed by savanna $(29.17 \%)$. Most of the interviewed households carried out various agricultural activities in forest according to the giblet burnt 
land method, for maintaining the soil fertility. These are indeed richer under forest table setting, along with this availability of water raised more which help them to struggle against the adventitious herbs (bad herbs) more comfortably.

\subsection{Promotion of agriculture in the Districts of Lower-Ueleand Upper-Uélé}

According to Hubert et al. (2006) the soil is an economic, political, social and cultural property in Africa. The land systems are strongly influenced by the colonial inheritance and customary systems. The positive right associated with the regulation, access of property, control \& exploitation of the natural resources and resolution of local conflicts supports the agricultural development. Furthermore, for the development of local economic, local policies should be developing that should be oriented toward the action and can prove the local potentials.

The dynamics that enliven the local population as entrepreneur and can pull advantage of the governmental policies along with the external help such as subsidiary, creativity and solidarity. Local development authority should take some better organized initiatives which implies focused on the individual. Better take some initiatives to get organized henceforth. The individual person should be in the center for the development, it is therefore required to reinforce the human capital. The better tools for the local agriculture development are mechanization of agriculture, popularization of agricultural based government policies, development of regional infrastructure, the politics of decentralization, proper local governance, the citizen involvement in the government policies, financing via local tax system and international agencies. If anyone wants to promote agriculture at larger scale and reduce poverty, they should not only emphasize on the development of agriculture but should also emphasize on the development of the small or medium agriculture based industries.

The development of these industries requires setting of suitable industrial policies. Along with this it is required to reinforce the necessary infrastructure and services required for the development of institutional farming environment. Furthermore, to arouse awareness, spread information, share data of experience and to modify the attitudes the processes of communication and training in the agricultural domain are indispensable. The accent should put on the improvement of the policies, working of institutions and increase in the investments could accelerate the expansion of the agricultural production to carry it to the levels that permit to reduce the under exploitation of agriculture, farming poverty and improve food security (Rapport, 2011).

Sensitization, formation, literacy, information to increase the levels of the consciences, knowledge and expertise of the management of farmers, raise of agriculture, entrepreneurship, supervision, popularization, research and communications are also essential to the lasting agricultural and farming development.

A steady macroeconomic environment constitutes an essential element for the global growth, which entails turn an expansion of the markets in terms of agricultural products and encouraging the confidence of the investors. However, many of these constraints can be surmounted the establishment of ties between farmers and traders. The important findings drawn from the study revealed that if anyone wish to encourage the expansion of agriculture, it is necessary to have a certain number of factors that compensate the "handicap" faced by the farming sector in domains such as the infrastructure, agrarian reform, social services, technology, circuits of merchandising and the availability of country credits and to put in place a suitable institutional environment.

Nevertheless, report of the Word Bank on poverty (2000), concentrates on the reforms concerning "governance" (or the political and institutional structures of the countries). On the other side, the "normative" setting of the World Bank rests on three concepts viz opportunities, the authorization and security. The first sends back to the working economy and reforms to achieve so that the poor can take advantage of the" economic opportunities ". The second term, empowerment, is rather to join with what the UNDP understands by" governance ". Finally "Security "covers the measures and social policies aiming to permit a better management of the risks for the poor populations.

This difference undoubtedly comes from the fact that the term of "governance" is a term including, capable to absorb any other dimension of political or economic order. Farmers must make a good choice of their leaders, especially those with agricultural leadership. It is essential that the farmers, men as women, participate in the whole process of clarification of an agricultural politics adapted and generally accepted and adopted by those who could make the most of it.

\section{Conclusion and suggestions}

Majority of the Lower and Upper Uele districts farmers have low level of instruction, deprived financing, non-adapted agricultural policies, traditional agricultural techniques, manual agriculture like under-exploited factors. Furthermore the farmers of these districts have lack of seriousness for the betterment of resources and this thing prevents them from generating the necessary investments to achieve their objectives of development in agriculture. The investments having the tendency to increase the capacity of agriculture production but it cannot be carried out only by material holding; for this diffusion of scientific knowledge and better agricultural technology are also required. It is therefore very important for the authorities to create a favorable climate for the investments in order to improve the levels of productivity and to facilitate the indispensable structural transformations. 
To improve the incitement to the investment competent authorities must adopt the policies having a tendency to improve the access of markets, manage the diffusion of information, fix suitable norms and provide an adequate legal and authorized setting. With this these authorities should create a favorable climate and an inciting setting organized to encourage the investments as well as the technologies for the lasting development of the agricultural sector.

Generally peoples believed that with political stability, a very definite and respected institutional setting are also required. Moreover, it is necessary to carry out a strong complementarity between the public and private investments to sustain the growth of agriculture.

The authorities must invest in the important elements of public sectors such as research, agrarian reform, popularization and infrastructure, they should particularly concern on the development of roads, railways, education and the development of norms. A conception and staggering should be reform, instability in the general constitute policies should be removed with this main sources of difficulties faced by the agriculture under-exploitation programs should be reform.

- Some of the important tasks which should be undertake for the improvement of the Uele districts agriculture are Re-launching of agriculture;

- Should established the factories for production of cattle food;

- Farmers should encourage for the integrated agriculture production system fish culture and animal breeding;

- Accelerate the rehabilitation of "INERABambesa" and "Le Service National des Semences" (SENASEM) of Dingila station;

- Reinforce the capacities of farmers, research staffs, National Service of the agricultural statistics and markets;

- Should establish a clear networks of transportation (roads in priority, railways, the river Uélé) to open the zones of production;

- Bestow the agricultural credit to the organized peasants;

- $\quad$ Developing the farming markets;

- Informing the population through the Media.

The farmers on their turns must henceforth take the initiatives and get organized.

\section{Conflict of interest}

Authors would hereby like to declare that there is no conflict of interests that could possibly arise.

\section{References}

ACF (2008) Enquête nutritionnelle anthropométrique. Réalisée du 30 juillet au 3 août 2008 dans la zone de santé de Buta.

Anatole R (1967) La Fécondité des populations congolaises. Paris-La Haye : Mouton.

Chausse JP, Kembola T, NGONDE R (2012) "L'agriculture: pierre angulaire de l'économie de la RDC", dans Johannes Herderschee, Daniel Mukoko Samba et Moïse Tshimenga Tshibangu (éditeurs), Résilience d'un Géant Africain : Accélérer la Croissance et Promouvoir l'Emploi en République Démocratique du Congo, Volume II : Etudes sectorielles, MÉDIASPAUL, Kinshasa, Pp 1-97.

DEPARTEMENT DE L'AGRICULTURE ET DU DEVELOPPEMENT RURAL (1992) Plan de relance agricole 1982-1984, SOFIAC, Paris, Pp 199.

Donald L (2012) Le chi-carré, approche quantitative, Centre de recherche et de développement en éducation (CRDE), Université de Moncton, Canada.

Hubert OM, Gnisci D, Hitimana L (2006) Les réformes foncières en Afrique de l'Ouest, Secrétariat du Club du Shael et de l'Afrique de l'Ouest Pp 71.

Jeníček V, Grófová Š (2015) The least developed countries the case of the Congo D.R. Agricultural Economics, Czech 61: 135-148. doi: 10.17221/49/2014-AGRICECON

Monographie de la Province Orientale (2005) Unité de Pilotage du Processus DSRP du Ministère du Plan, Pp. 35-36.

Otchia CS (2014) Agricultural Modernization, Structural Change and Pro-poor Growth: Policy Options for the Democratic Republic of Congo. Journal of Economic Structures 3 :1-43. doi 10.1186/s40008-014-0008-x.

Otchia CS (2014) Distributional and poverty effects of agriculture trade liberalisation: the case of the Democratic Republic of Congo. Paper prepared for the UNCTAD Virtual Institute project on trade and poverty, UNCTAD-VI, Geneva.

Porkess R (1988) Dictionary of statistics, Collins, Pp. 267.

RAPPORT, (2011), Développement local : concepts, stratégies et benchmarking, $\quad 1$ ère contribution de MIPMPEP (Ministère de l'Industrie, de la Petite et Moyenne Entreprise et de la Promotion de l'investissement) au débat sur la promotion du développement local en Algérie.

Tshonda JO, Akude JDD, Stroobant É, Sita CK, Etambala MZ, Simons E, Krawczyk J, Laghmouch M (2014) Bas-Uélé, Pouvoirs locaux et économie agricole : héritages d'un passé 
Factors responsible for under exploitation and Promotion of agriculture in of the Lower and Upper Uele Districts.

brouillé, Musée royal de l'Afrique centrale, Leuvensesteenweg 13 B-3080 Tervuren, Pp.516

Ulloa A, Katz F, Kekeh N (2009) Democratic Republic of the Congo: A Study of Binding Constraints. www.hks.harvard.edu/fs/drodrik/Growth\%20diagnostics\%20p apers/DRC_Growth_Diagnostic.pdf.
World Bank (2000) World development report: attacking poverty. Oxford University Press, New York

World Bank (2009) Guide to Rating Gender-Responsiveness in Project Design, Unpublished document, World Bank, Washington, DC 